Pacific Journal of Mathematics

PRRMIS I P Probuctro of RNGS 


\title{
PRIMES IN PRODUCTS OF RINGS
}

\author{
Joel Cunningham
}

This paper is an elementary note which indicates how Harrison's primes sit in certain kinds of rings. It is proved that primes behave nicely under finite direct products. Also it is shown that any nil ideal is a subset of every prime. This gives information about the primes of artinian rings.

By ring we mean associative ring with identity.

Harrison introduced the notion of a prime of a ring in [2]. For a ring $R$, a preprime of $R$ is a subset of $R$ which is closed under addition and multiplication and does not contain -1. A prime of $R$ is a preprime of $R$ which is not properly contained in any other preprime of $R$. A prime is called finite if it does not contain 1 .

The collection $Y(R)$ of all primes of $R$ is topologized by taking as a basis all subsets $V(E)$ where $E$ is a finite subset of $R$ and $V(E)=\{P \in Y(R) \mid P \cap E=\phi\}$.

Some important special cases of the following result were known to Harrison and his students as early as 1966. However the proofs known then were long and depended heavily on the special conditions. One of the cases in which the result was known was where the rings are both commutative and all the primes are taken to be finite. This case is also handled by Connell in [1] where he deals with a notion of prime which generalizes the notion of a finite prime of a commutative ring.

THEOREM 1. Let $R$ and $S$ be rings. The primes of the direct product $R \oplus S$ are exactly the subsets $P \times S=\{(p, s) \in R \oplus S \mid p \in P\}$ where $P$ is a prime of $R$ and $R \times Q=\{(r, q) \in R \oplus S \mid q \in Q\}$ where $Q$ is a prime of $S$.

Proof. Let $\Pi_{R}: R \oplus S \rightarrow R$ and $\Pi_{S}: R \oplus S \rightarrow S$ be the canonical projections.

Let $H$ be any prime of $R \oplus S$. Clearly $\Pi_{R}(H)$ and $\Pi_{S}(H)$ are both closed under addition and multiplication. Just suppose $-1 \in \Pi_{R}(H)$ and $-1 \in \Pi_{S}(H)$. Then there exists $s \in S$ and $r \in R$ with $(-1, s)$ and $(r,-1)$ in $H$. But then $(-1,-1)=(-1, s)(r,-1)+(-1, s)+(r,-1)$ is in $H$, a contradiction. So say $-1 \notin \Pi_{R}(H)$. Then $\Pi_{R}(H)$ is a preprime of $R$. Choose a prime $P$ of $R$ such that $\Pi_{R}(H) \subset P$. Then clearly $P \times S$ is a preprime of $R \oplus S$ and $H \subset P \times S$. So $H=P \times S$. Similarly if $-1 \notin \Pi_{S}(H)$ then there exists a prime $Q$ of $S$ such that $H=R \times Q$. 
Now let $P$ be a prime of $R$. Then $P \times S$ is a preprime of $R \oplus S$. Let $H$ be a prime of $R \oplus S$ containing $P \times S$. Using the above part of the proof one checks that $H=P^{\prime} \times S$ for some prime $P^{\prime}$ of $R$. But then since $P$ is a prime, $P=P^{\prime}$. So $P \times S$ is a prime. Similarly, for $Q \in Y(S), R \times Q \in Y(R \oplus S)$. do have

In the above, no mention is made of the topology. However, we

COROLlaRY 2. For any nonzero rings $R$ and $S, Y(R \oplus S)$ is naturally homeomorphic to $Y(R) \cup Y(S)$ with the disjoint union topology.

Proof. Let $A=\{P \times S \mid P \in Y(R)\}$ and $B=\{R \times Q \mid Q \in Y(S)\}$. Since $R$ and $S$ are both nonzero, $A$ and $B$ are disjoint. Using Theorem 1 we have $Y(R \oplus S)=A \cup B$ and that $A=V(\{(-1,0)\})$ and $B=V(\{(0,-1)\})$, so $A$ and $B$ are both open. Noting that $A$ is naturally homeomorphic with $Y(R)$ and $B$ is naturally homeomorphic with $Y(S)$ we have the corollary.

Clearly Theorem 1 and its corollary can be extended to any finite product of rings. However the corresponding statement for an infinite product of rings is not true. In the infinite case there can be primes other than the ones given by one coordinate.

It follows from Corollary 2 that for an arbitrary ring $R, Y(R)$ is far from connected. However, for $R$ an integral domain $Y(R)$ is connected; in fact we have

Proposition 3. If $R$ is a commutative integral domain, then $Y(R)$ is irreducible, i.e., any two nonvoid open subsets of $Y(R)$ have nonvoid intersection.

Proof. This follows easily by using the result of Harrison and Manis [2, 2.6]. For if $V(G)$ and $V(H)$ are two nonvoid basic open subsets of $Y(R)$ then $0 \notin G \cup H$ and so no power of the product of the elements of $G \cup H$ is zero. Hence by [2,2.6] there is a prime $P$ with $P \in V(G \cup H)=V(G) \cap V(H)$.

In order to use Theorem 1 to study $Y(R)$ for artinian rings we need the following two observations.

Note 4. For any ring $R$ and any two-sided ideal a of $R$ the space $Y(R / \mathfrak{a})$ is naturally homeomorphic to the subspace of $Y(R)$ composed of all primes containing $a$. The homeomorphism is given by $P \rightarrow f(P)$ where $f: R \rightarrow R / \mathfrak{a}$ is the natural map.

This note is made more interesting by the following 
Proposition 5. Any nil ideal of a ring $R$ is contained in every prime of $R$.

Proof. Let $N$ be a nil ideal of $R$ and $P$ a prime of $R$. Just suppose $N \not \supset P$, then $P \subsetneq N+P$ and $N+P$ is closed under addition and multiplication. So $-1 \in N+P$. Say $-1=n+p$ for $n \in N$ and $p \in P$. Then $p+1$ is in $N$ so there exists a positive integer $m$ such that

Hence

$$
0=(p+1)^{m}=\sum_{k=0}^{m}\left(\begin{array}{c}
m \\
k
\end{array}\right) p^{k}
$$

a contradiction.

$$
-1=\sum_{k=1}^{m}\left(\begin{array}{c}
m \\
k
\end{array}\right) p^{k} \in P,
$$

Now if $R$ is an artinian ring with Jacobson radical $J$, then $J$ is nilpotent so by the above proposition $J$ is contained in every prime of $R . \quad R / J$ has an Artin-Wedderburn decomposition

$$
R / J \simeq M_{n_{1}}\left(D_{1}\right) \oplus \cdots \oplus M_{n_{k}}\left(D_{k}\right)
$$

as a direct product of finitely many full matrix rings over division rings. Thus using Note 4 we have

COROLlaRY 6. If $R$ is artinian with notation as above, $Y(R)$ is naturally homeomorphic to the disjoint union

$$
\bigcup_{i=1}^{k} Y\left(M_{n_{i}}\left(D_{i}\right)\right) \text {. }
$$

In the special case where $R$ is a finite ring the $D_{i}$ are all finite fields and in this case $Y\left(M_{n_{i}}\left(D_{i}\right)\right)$ is completely analyzed by Rutherford in [3]. There it is shown that for any finite dimensional vector space $V$ over a locally finite field $K$, the primes of the full ring $E$ of $K$ endomorphisms of $V$ are exactly the subsets $T(W, L) \subset E$ where $L$ is a subspace of $V$ and $W$ is a subspace of $L$ with $\operatorname{dim}_{K}(L / W)=1$ and $T(W, L)=\{f \in E \mid f(L) \subset W\}$. Using this and Corollary 6 we have a complete analysis of $Y(R)$ for finite rings.

\section{REFERENCES}

1. I. G. Connell, A natural transformation of the spec functor, J. Algebra, 10 (1968), 69-91.

2. D. K. Harrison, Finite and infinite primes for rings and fields, Mem. Amer. Math. Soc., No. 68 (1966).

3. H. G. Rutherford, Characterizing primes in some noncommutative rings, Pacific J. Math., 27 (1968), 387-392.

Received October 21, 1970. 



\title{
PACIFIC JOURNAL OF MATHEMATICS
}

\author{
EDITORS
}

\author{
H. SAMELSON \\ Stanford University \\ Stanford, California 94305 \\ C. R. HOBBY \\ University of Washington \\ Seattle, Washington 98105
}

J. DugundJI

Department of Mathematics

University of Southern California

Los Angeles, California 90007

RICHARD ARENS

University of California

Los Angeles, California 90024

\section{ASSOCIATE EDITORS}
E. F. BeCKenBaCH
B. H. NeUMANN
F. WOLF
K. Yoshida

\section{SUPPORTING INSTITUTIONS}

\author{
UNIVERSITY OF BRITISH COLUMBIA \\ CALIFORNIA INSTITUTE OF TECHNOLOGY \\ UNIVERSITY OF CALIFORNIA \\ MONTANA STATE UNIVERSITY \\ UNIVERSITY OF NEVADA \\ NEW MEXICO STATE UNIVERSITY \\ OREGON STATE UNIVERSITY \\ UNIVERSITY OF OREGON \\ OSAKA UNIVERSITY
}

\author{
UNIVERSITY OF SOUTHERN CALIFORNIA \\ STANFORD UNIVERSITY \\ UNIVERSITY OF TOKYO \\ UNIVERSITY OF UTAH \\ WASHINGTON STATE UNIVERSITY \\ UNIVERSITY OF WASHINGTON \\ AMERICAN MATHEMATICAL SOCIETY \\ NAVAL WEAPONS CENTER
}

The Supporting Institutions listed above contribute to the cost of publication of this Journal, but they are not owners or publishers and have no responsibility for its content or policies.

Mathematical papers intended for publication in the Pacific Journal of Mathematics should be in typed form or offset-reproduced, (not dittoed), double spaced with large margins. Underline Greek letters in red, German in green, and script in blue. The first paragraph or two must be capable of being used separately as a synopsis of the entire paper. The editorial "we" must not be used in the synopsis, and items of the bibliography should not be cited there unless absolutely necessary, in which case they must be identified by author and Journal, rather than by item number. Manuscripts, in duplicate if possible, may be sent to any one of the four editors. Please classify according to the scheme of Math. Rev. Index to Vol. 39. All other communications to the editors should be addressed to the managing editor, Richard Arens, University of California, Los Angeles, California, 90024.

50 reprints are provided free for each article; additional copies may be obtained at cost in multiples of 50 .

The Pacific Journal of Mathematics is published monthly. Effective with Volume 16 the price per volume (3 numbers) is $\$ 8.00$; single issues, $\$ 3.00$. Special price for current issues to individual faculty members of supporting institutions and to individual members of the American Mathematical Society: $\$ 4.00$ per volume; single issues $\$ 1.50$. Back numbers are available.

Subscriptions, orders for back numbers, and changes of address should be sent to Pacific Journal of Mathematics, 103 Highland Boulevard, Berkeley, California, 94708.

PUBLISHED BY PACIFIC JOURNAL OF MATHEMATICS, A NON-PROFIT CORPORATION

Printed at Kokusai Bunken Insatsusha (International Academic Printing Co., Ltd.), 270, 3chome Totsuka-cho, Shinjuku-ku, Tokyo 160, Japan. 


\section{Pacific Journal of Mathematics}

\section{Vol. 39, No. $3 \quad$ July, 1971}

William O'Bannon Alltop, 5-designs in affine spaces ................... 547

B. G. Basmaji, Real-valued characters of metacyclic groups ................. 553

Miroslav Benda, On saturated reduced products....................... 557

J. T. Borrego, Haskell Cohen and Esmond Ernest Devun, Uniquely representable semigroups. II.......................................

George Lee Cain Jr. and Mohammed Zuhair Zaki Nashed, Fixed points and stability for a sum of two operators in locally convex spaces ....................

Donald Richard Chalice, Restrictions of Banach function spaces ...............

Eugene Frank Cornelius, Jr., A generalization of separable groups ..............

Joel L. Cunningham, Primes in products of rings ......................

Robert Alan Morris, On the Brauer group of $Z$.

593

603

615

David Earl Dobbs, Amitsur cohomology of algebraic number rings ...............

Charles F. Dunkl and Donald Edward Ramirez, Fourier-Stieltjes transforms and

weakly almost periodic functionals for compact groups ...................

Hicham Fakhoury, Structures uniformes faibles sur une classe de cônes et

d'ensembles convexes ......................................

Leslie R. Fletcher, A note on C $\theta \theta$-groups.

Humphrey Sek-Ching Fong and Louis Sucheston, On the ratio ergodic theorem for

semi-groups............................................

James Arthur Gerhard, Subdirectly irreducible idempotent semigroups ...........

Thomas Eric Hall, Orthodox semigroups.....................

Marcel Herzog, $C \theta \theta$-groups involving no Suzuki groups ..........

669

687

John Walter Hinrichsen, Concerning web-like continua ..........

691

Frank Norris Huggins, A generalization of a theorem of F. Riesz.

695

Carlos Johnson, Jr., On certain poset and semilattice homomorphisms

703

Alan Leslie Lambert, Strictly cyclic operator algebras ...........

717

Howard Wilson Lambert, Planar surfaces in knot manifolds . . .

727

Robert Allen McCoy, Groups of homeomorphisms of normed linear spaces ....... 735

T. S. Nanjundiah, Refinements of Wallis's estimate and their generalizations ...... 745

Roger David Nussbaum, A geometric approach to the fixed point index .......... 751

John Emanuel de Pillis, Convexity properties of a generalized numerical range .... 767

Donald C. Ramsey, Generating monomials for finite semigroups ....

783

William T. Reid, A disconjugacy criterion for higher order linear vector differential equations...

Roger Allen Wiegand, Modules over universal regular rings...

Kung-Wei Yang, Compact functors in categories of non-archimedean Banach

spaces.

R. Grant Woods, Correction to: "Co-absolutes of remainders of Stone-Čech compactifications".

Ronald Owen Fulp, Correction to: "Tensor and torsion products of

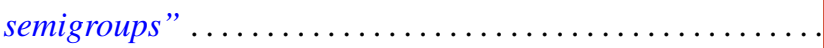

Bruce Alan Barnes, Correction to: "Banach algebras which are ideals in a banach 